\title{
EMBRIOGÊNESE SOMÁTICA DIRETA EM EXPLANTES FOLIARES DE Coffea arabica L. CV. ACAIÁ CERRADO: EFEITO DE CINETINA E ÁCIDO GIBERÉLICO ${ }^{1}$
}

\author{
Direct somatic embryogenesis in Coffea arabica L. cv. Acaiá Cerrado: \\ Kinetin and giberelic acid effects
}

\author{
Alba Regina Pereira ${ }^{2}$, Samuel Pereira de Carvalho ${ }^{3}$, Moacir Pasqual ${ }^{3}$, Flávia Carvalho Santos
}

\begin{abstract}
RESUMO
Objetivou-se estudar o efeito da cinetina, $\mathrm{GA}_{3}$ e ANA na indução in vitro de embriões somáticos de cafeeiro pela via direta. Segmentos foliares retirados de plântulas cultivadas in vitro foram inoculados em meio de cultura 'MS' com 50\% dos sais contendo as seguintes combinações de cinetina $\left(0 ; 1 ; 2 ; 4\right.$ e $\left.8 \mathrm{mg} \mathrm{L}^{-1}\right)$ e GA $\left(0 ; 2,5 ; 5 ; 10\right.$ e $\left.20 \mathrm{mg} \mathrm{L}^{-1}\right)$. Os meios de cultura utilizados tiveram pH ajustado para $5,8 \pm 1$ antes de serem autoclavados. O experimento foi mantido em sala de crescimento a $25 \pm 1{ }^{\circ} \mathrm{C}$. Avaliou-se número total de embriões somáticos, o número de embriões cotiledonares, o número de embriões torpedo e a média dos comprimentos dos embriões. A ação combinada entre cinetina, GA e ANA estimulou a indução de embriões somáticos pela via direta. O maior comprimento de embriões foi observado quando se utilizou $8 \mathrm{mg} \mathrm{L}^{-1}$ de cinetina e $8,0 \mathrm{mg} \mathrm{L}^{-1}$ de ANA ou $17 \mathrm{mg} \mathrm{L}^{-1} \mathrm{de} \mathrm{GA}_{3}$ e $8,0 \mathrm{mg} \mathrm{L}^{-1}$ de ANA isoladamente.
\end{abstract}

Termos para indexação: Embriões somáticos, reguladores de crescimento, cafeeiro.

\section{ABSTRACT}

It was aimed to study kinetin, $\mathrm{GA}_{3}$ and ANA effects in the in vitro induction of direct somatics embryos. Leaf segments withdrawn from plantlets in vitro were inoculated in 'MS' $50 \%$ containing the following combination of kinetin $\left(0 ; 1 ; 2 ; 4\right.$ and $\left.8 \mathrm{mg} \mathrm{L}^{-1}\right)$ and $\mathrm{GA}_{3}\left(0 ; 2,5 ; 5 ; 10\right.$ and $\left.20 \mathrm{mg} \mathrm{L}^{-1}\right)$. The culture media utilized had their $\mathrm{pH}$ adjusted to $5,8 \pm 1$ before being autoclaved. The experiment was carried out growth room at $25 \pm 1{ }^{\circ} \mathrm{C}$. Total number of embryos, number of embryos cotiledonar, number of embryos of torped and length of embryo were evaluated. The combination between kinetin and GA promoved induction of embryos. The use of kinetin $8 \mathrm{mg} \mathrm{L}^{-1}$ and $\mathrm{GA}_{3} 17 \mathrm{mg} \mathrm{L}^{-1}$ not associate in medium with $8,0 \mathrm{mg} \mathrm{L}^{-1}$ of ANA, promoter higher rates in vitro.

Index terms: Somatics embryos, growth regulators, Coffea.

(Recebido 3 de março de 2005 e aprovado em 8 de dezembro de 2005)

\section{INTRODUÇÃO}

O sucesso dos programas de melhoramento genético tem colocado à disposição dos cafeicultores, cultivares mais adaptadas, produtivas e que atendem às necessidades dos consumidores. Entretanto, o melhoramento genético do cafeeiro através de métodos convencionais,principalmente hibridação, retrocruzamentos e cruzamentos interespecíficos, seguidos da seleção de populações, avaliação de progênies, é um processo demorado, podendo levar mais de trinta anos para se obter uma nova cultivar (ALMEIDA et al., 2000). Dessa forma, o desenvolvimento de técnicas para propagação acelerada de plantas de cafeeiro é fundamental para aumentar a taxa de multiplicação e possibilitar a rápida difusão de novas cultivares.

Nesse contexto, a propagação vegetativa é indicada para multiplicação de cultivares de alta produtividade e resistentes a enfermidades, garantindo uniformidade nos povoamentos e mantendo o ganho genético obtido na seleção. No entanto, a multiplicação vegetativa pelos métodos convencionais deve limitar-se à utilização de fragmentos de ramos ortotrópicos, sempre em número limitado (DUBLIN, 1984). Em contrapartida, as dificuldades de multiplicação podem ser minimizadas por meio da propagação vegetativa in vitro.

Um importante método de multiplicação in vitro de plantas de Coffea é a embriogênese somática, que consiste no desenvolvimento de embrióides a partir de células haplóides ou somáticas diplóides, sem que haja a fusão de gametas, e que possibilita micropropagação acelerada de clones superiores e a manutenção de híbridos interespecíficos.

Segundo Sharp et al. (1980), embriogênese somática in vitro apresenta dois padrões básicos de desenvolvimento de embriões: direta, na qual os embriões somáticos originam-se diretamente de tecidos de matrizes sem a formação de estádios intermediários de calos; e indireta, na qual os embriões somáticos se formam a partir

\footnotetext{
Parte da dissertação apresentada à Universidade Federal de Lavras/UFLA - Cx. P. 3037 - 37200-000 - Lavras, MG, pelo primeiro autor.

${ }^{2}$ Rua Pacheco Leão, n 915 - Jardim Botânico - 22.460-030 - Rio de Janeiro, RJ - alba@jbrj.gov.br

${ }_{3}$ Professor Titular do Departamento de Agricultura/DAG - Universidade Federal de Lavras/UFLA - Cx. P. 3037 - 37.200-000 - Lavras, MG.
} 
de calos, que apresentam células em diferentes estádios de diferenciação. Em ambos os padrões, o embrião somático segue a mesma sequiência de desenvolvimento do zigótico, ou seja, a passagem pelos estádios globular, cordiforme, torpedo e cotiledonar (GUERRA et al., 1999).

Segundo Vieira \& Kobayashi (2000), uma característica diferencial entre estes dois padrões de desenvolvimento embriogênico é a resposta à ação de reguladores de crescimento. Enquanto a embriogênese direta caracteriza-se pelo cultivo dos explantes em um único meio de cultura com a adição de apenas uma citocinina, a indireta requer alta relação auxina/citocinina para a formação de calos não diferenciados em um meio de cultura inicial e baixa relação para a indução de calos embriogênicos durante culturas subseqüentes.

Os primeiros trabalhos conhecidos de embriogênese somática no gênero Coffea foram realizados por Starisky (1970), que obteve rápida proliferação de calos na espécie $C$. arabica e embrióides e plântulas com explantes de $C$. canephora. Desde então se têm desenvolvido pesquisas sobre a embriogênese somática no cafeeiro em diversos países (CORDEIRO, 1999; SREENATH, 2000).

As auxinas e citocininas têm papel fundamental na embriogênese somática de várias espécies de plantas. Algumas espécies necessitam de meio suplementado com ácido giberélico para o desenvolvimento de embriões somáticos.

Vieira \& Kobayashi (2000) afirmam que $C$. canephora tem sido utilizada como espécie modelo na grande maioria dos trabalhos em embriogênese direta. Existe uma grande diferença entre $C$. canephora e $C$. arabica quanto à indução de embriogênese direta em explantes foliares. Enquanto que para a primeira espécie é relativamente fácil desencadear a formação de embriões somáticos em meio de cultura suplementado somente com citocininas (FUENTES et al., 2000), há poucos relatos da obtenção de embriogênese somática direta em $C$. arabica.

Objetivou-se, com este trabalho, induzir a formação de embriões somáticos pela via direta com adição de cinetina e $\mathrm{GA}_{3}$ ao meio de cultura.

\section{MATERIAL E MÉTODOS}

Os experimentos foram conduzidos no Laboratório de Cultura de Tecidos Vegetais do Departamento de Agricultura da Universidade Federal de Lavras, em Lavras, MG.

Os explantes utilizados foram segmentos de folhas de Coffea arabica cv. Acaiá Cerrado, com tamanho médio de $1 \mathrm{~cm}^{2}$, provenientes de partes aéreas de plântulas micropropagadas, originadas de cultura de embriões e estabelecidas in vitro durante 60 dias.

Os tratamentos consistiram da combinação de cinco concentrações de cinetina $\left(0 ; 1,0 ; 2,0 ; 4,0\right.$ e 8,0 mg. $\left.\mathrm{L}^{-1}\right)$ e cinco concentrações de $\mathrm{GA}_{3}\left(0 ; 2,5 ; 5,0 ; 10,0\right.$ e 20,0 mg.L $\left.\mathrm{L}^{-1}\right)$ adicionados ao meio 'MS' (MURASHIGE \& SKOOG, 1962) com 50\% dos sais, 8,0 mg. $\mathrm{L}^{-1}$ de ANA, $100 \mathrm{mg} . \mathrm{L}^{-1}$ de caseína hidrolisada e $400 \mathrm{mg} . \mathrm{L}^{-1}$ de extrato de malte.

Os explantes de C. arabica foram inoculados, em câmara de fluxo laminar horizontal, individualmente em tubos de ensaio contendo $15 \mathrm{~mL}$ de meio de cultura. Após a inoculação, os tubos contendo os explantes foram mantidos em sala de crescimento sob condições de total ausência de luz, com temperatura de $25 \pm 1^{\circ} \mathrm{C}$.

$\mathrm{O}$ delineamento experimental utilizado foi o inteiramente casualizado, em esquema fatorial 5 x 5, com quatro repetições de três tubos cada uma.

Após 150 dias, o experimento foi avaliado quanto ao número total de embriões, ao número de embriões no estádio torpedo, ao número de embriões no estádio cotiledonar e as médias dos comprimentos do embrióides.

\section{RESULTADOS E DISCUSSÃO}

\section{Número total de embriões somáticos}

$\mathrm{O}$ efeito das concentrações variadas de cinetina e $\mathrm{GA}_{3}$ e fixa de ANA no número total de embriões pode ser observado na Figura 1. Foram formados 45 embriões somáticos em explantes foliares quando se adicionou ao meio de cultura cinetina na concentração de $5,6 \mathrm{mg} \mathrm{L}^{-1}$ combinada com $10 \mathrm{mg} \mathrm{L}^{-1}$ de $\mathrm{GA}_{3}$ (Figura 1A). Com a utilização de 5,8 $\mathrm{mg} \mathrm{L}^{-1}$ de cinetina combinada com $20 \mathrm{mg} \mathrm{L}^{-1}$ de $\mathrm{GA}_{3}$, pode-se observar a formação de 44 embriões somáticos. Dessa forma, como a diferença é mínima, justifica-se a utilização do meio de cultura com a adição de $10 \mathrm{mg} \mathrm{L}^{-1}$ de $\mathrm{GA}_{3}$, com o objetivo de redução de custos. Contudo, concentrações acima de $6 \mathrm{mg} \mathrm{L}^{-1}$ de cinetina associadas a 10 e $20 \mathrm{mg} \mathrm{L}^{-1}$ de $\mathrm{GA}_{3}$ promoveram inibição e redução na formação de embrióides, provavelmente causada por desbalanço hormonal, da relação endógena entre auxinas e giberelinas dos explantes.

Concentrações superiores a $8 \mathrm{mg} \mathrm{L}^{-1}$ de cinetina quando combinadas com 2,5 e 5,0 $\mathrm{mg} \mathrm{L}^{-1}$ de $\mathrm{GA}_{3}$ podem proporcionar um aumento no número de embriões somáticos. Essas mesmas concentrações de $\mathrm{GA}_{3}$ quando associadas a valores entre 2 e $6 \mathrm{mg} \mathrm{L}^{-1}$ de cinetina reduziram o número de embrióides.

O número de embriões somáticos obtidos na ausência da cinetina, em todas as concentrações de $\mathrm{GA}_{3}$ foi inferior 
quandocomparado aos demais tratamentos, evidenciando-se assim a importância desse fitoregulador para a indução de embriões em Coffea arabica cv. Acaiá Cerrado. A concentração de $2 \mathrm{mg} \mathrm{L}^{-1}$ de cinetina quando combinada às concentrações de $10 \mathrm{mg} \mathrm{L}^{-1}$ e $20 \mathrm{mg} \mathrm{L}^{-1}$ de $\mathrm{GA}_{3}$ também mostrou-se menos eficiente na indução de embriões somáticos. Possivelmente, nesse caso, maiores concentrações de cinetina são requeridas para se obter maior número de embriões somáticos.

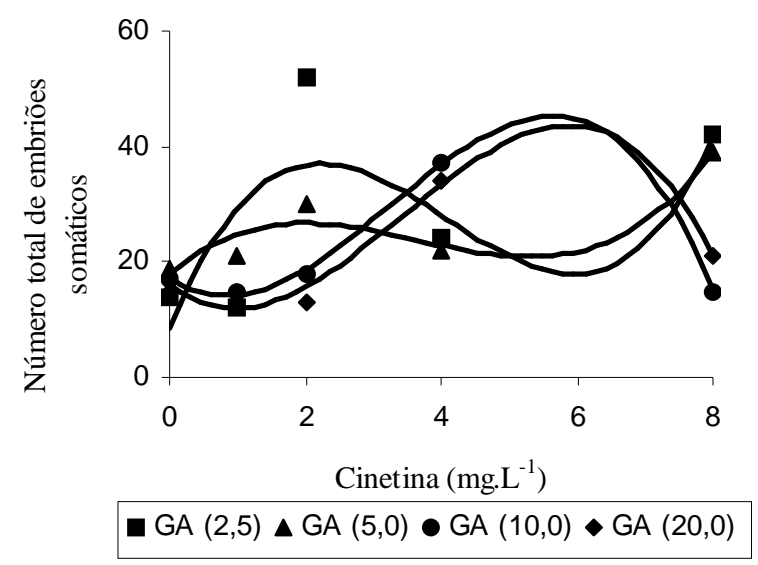

$$
\begin{array}{ll}
\mathrm{Y}_{0}=\mathrm{ns} & \\
\mathrm{Y}_{2,5}=8,2902+29,463 \mathrm{x}-9,0942 \mathrm{x}^{2}+0,7417 \mathrm{x}^{3} & \mathrm{R}^{2}=0,53 \\
\mathrm{Y}_{5,0}=17,757+10,25 \mathrm{x}-3,5407 \mathrm{x}^{2}+0,3238 \mathrm{x}^{3} & \mathrm{R}^{2}=0,90 \\
\mathrm{Y}_{10,0}=17,261-7,9614 \mathrm{x}+5,4662 \mathrm{x}^{2}-0,5633 \mathrm{x}^{3} & \mathrm{R}^{2}=0,98 \\
\mathrm{Y}_{20,0}=15,993-8,923 \mathrm{x}+5,4354 \mathrm{x}^{2}-0,5301 \mathrm{x}^{3} & \mathrm{R}^{2}=0,94
\end{array}
$$

FIGURA 1 - Efeito de concentrações de cinetina e $\mathrm{GA}_{3} \mathrm{e}$ a concentração fixa de ANA $\left(8,0 \mathrm{mg} \mathrm{L}^{-1}\right)$ no número total de embriões somáticos de Coffea arabica cv. Acaiá Cerrado. UFLA, Lavras-MG, 2004.

Resultados similares foram obtidos por Hatanaka et al. (1991), que estudando a indução de embriões somáticos a partir da embriogênese direta em folhas de Coffea canephora, obtiveram uma média de 100 embriões/ explante quando utilizaram cinetina na concentração de 5 $\mathrm{mg} \mathrm{L}^{-1}$.Demonstraram, ainda, que 2-iP e BAP também foram capazes de estimular o desenvolvimento de embriões somáticos originados por via direta e que as auxinas são altamente inibitórias para a formação de embrióides.

Já em relação ao regulador de crescimento $\mathrm{GA}_{3}$ utilizado no experimento, Carvalho et al. (1998) afirmaram que o $\mathrm{GA}_{3}$ contribui para o desenvolvimento de embrióides de cafeeiro.
O número de embriões somáticos diretos de $C$. arabica cv. Acaiá Cerrado obtido no presente trabalho, utilizando cinetina e $\mathrm{GA}_{3}$ foi inferior quando comparado aos resultados de embriogênese indireta em $C$. arabica cv. Obatã obtidos por Maciel et al. (2003), os quais obtiveram proliferação de calos utilizando 2,4-D e cinetina, alcançando na etapa posterior, uma média de 310 embriões/explante. Este comportamento está de acordo com Vieira \& Kobayashi (2000), que asseguram que a embriogênese indireta é preferencialmente utilizada para estudos de multiplicação clonal de plântulas de cafeeiro, pois geralmente proporciona a formação de maior número de embriões somáticos/ explante. Entretanto, a embriogênese direta pode manter em torno de $80 \%$ a constituição genética do genótipo doador (VIEIRA \& KOBAYASHI, 2000).

\section{Número de embriões cotiledonares}

Analisando-se o efeito das concentrações de cinetina e $\mathrm{GA}_{3}$ no número de embrióides cotiledonares (Figura 2), observa-se que a utilização de $20 \mathrm{mg} \mathrm{L}^{-1}$ de $\mathrm{GA}_{3}$ associada a 5,9 $\mathrm{mg} \mathrm{L}^{-1}$ de cinetina e $8,0 \mathrm{mg} \mathrm{L}^{-1}$ de ANA promoveu a formação de maior número de embriões cotiledonares (38). Porém, concentrações de cinetina superiores a $6 \mathrm{mg} \mathrm{L}^{-1}$ associadas a 10 e $20 \mathrm{mg} \mathrm{L}^{-1}{\mathrm{de} \mathrm{GA}_{3}}_{4}$

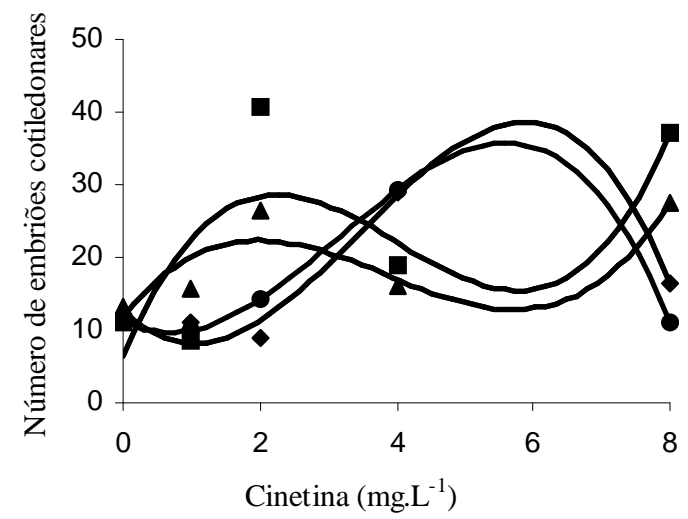

- GA $(2,5) \triangle \mathrm{GA}(5,0) \bullet \mathrm{GA}(10,0) \bullet \mathrm{GA}(20,0)$

$$
\begin{array}{ll}
\mathrm{Y}_{0}=\mathrm{ns} & \\
\mathrm{Y}_{2,5}=6,3957+22,677 \mathrm{x}-7,024 \mathrm{x}^{2}+0,5836 \mathrm{x}^{3} & \mathrm{R}^{2}=0,57 \\
\mathrm{Y}_{5,0}=11,813+12,094 \mathrm{x}-4,1336 \mathrm{x}^{2}+0,3584 \mathrm{x}^{3} & \mathrm{R}^{2}=0,78 \\
\mathrm{Y}_{10,0}=11,303-5,0036 \mathrm{x}+4,1305 \mathrm{x}^{2}-0,4387 \mathrm{x}^{3} & \mathrm{R}^{2}=0,97 \\
\mathrm{y}_{20,0}=12,901-9,6032 \mathrm{x}+5,4847 \mathrm{x}^{2}-0,5288 \mathrm{x}^{3} & \mathrm{R}^{2}=0,94
\end{array}
$$

FIGURA 2 - Efeito de concentrações de cinetina, $\mathrm{GA}_{3} \mathrm{e}$ concentração fixa de ANA $\left(8,0 \mathrm{mg} \mathrm{L}^{-1}\right)$ no número de embriões cotiledonares de Coffea arabica cv. Acaiá Cerrado. UFLA, Lavras-MG, 2004. 
proporcionaram redução no número de embriões, provavelmente devido ao desbalanço hormonal causado por esses reguladores de crescimento. Observa-se ainda que concentrações acima de $8 \mathrm{mg} \mathrm{L}^{-1}$ de cinetina quando combinadas com 2,5 e $5,0 \mathrm{mg} \mathrm{L}^{-1}$ de $\mathrm{GA}_{3}$ podem proporcionar um incremento no número de embriões cotiledonares.

\section{Número de embriões torpedo}

Maior número de embrióides no estádio torpedo (11) foi formado em explantes foliares quando se adicionou, ao meio de cultura, cinetina na concentração de $8 \mathrm{mg} \mathrm{L}^{-1}$ combinada com $5 \mathrm{mg} \mathrm{L}^{-1}$ de $\mathrm{GA}_{3}$ e $8,0 \mathrm{mg} \mathrm{L}^{-1}$ de ANA(Figura 3). Concentrações de cinetina superiores a $8 \mathrm{mg} \mathrm{L}^{-1}$ quando combinadas com 2,5 $\mathrm{mg} \mathrm{L}^{-1}$ de $\mathrm{GA}_{3}$ podem proporcionar um incremento no número de embriões torpedo. Nessa mesma concentração de $\mathrm{GA}_{3}$, quando associada a $2 \mathrm{mg} \mathrm{L}^{-1}$ de cinetina, pode-se observar a formação de 8,39 embriões.

$\mathrm{Na}$ ausência de cinetina, para ambas as concentrações de $\mathrm{GA}_{3}$ pode-se observar um menor número de embriões e que com $5 \mathrm{mg} \mathrm{L}^{-1}$ de $\mathrm{GA}_{3}$ foi maior que com 2,5 $\mathrm{mg} \mathrm{L}^{-1}$. Constata-se assim, a importância da utilização da cinetina no meio de cultura para a indução de embriões de cafeeiro.

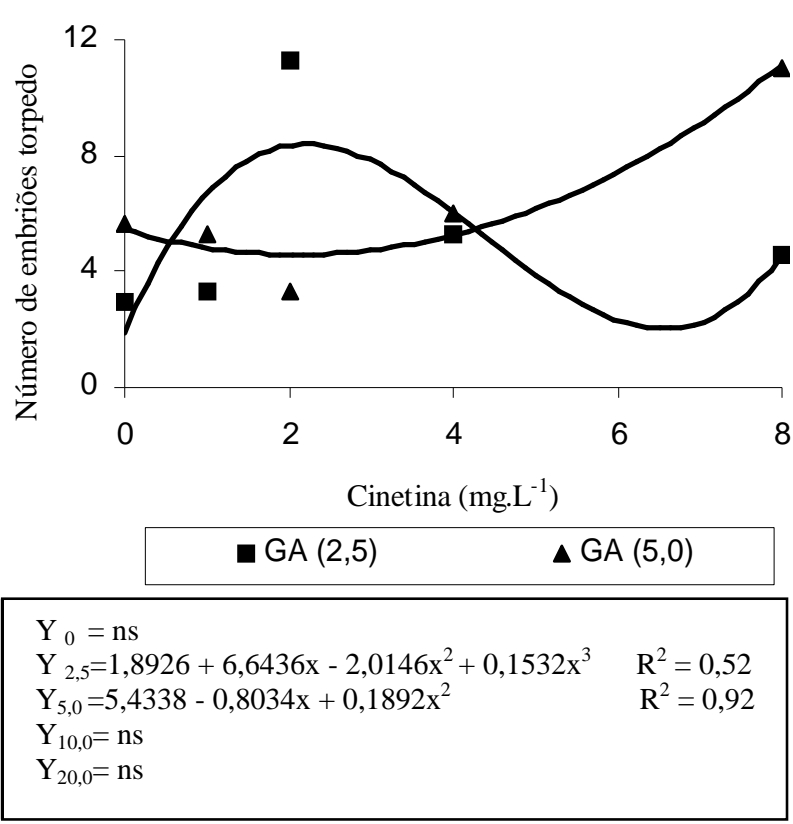

FIGURA 3 - Efeito de concentrações de cinetina, $\mathrm{GA}_{3} \mathrm{e}$ concentração fixa de ANA $\left(8,0 \mathrm{mg} \mathrm{L}^{-1}\right)$ no número de embriões torpedo de Coffea arabica cv. Acaiá Cerrado. UFLA, Lavras-MG, 2004.

\section{Comprimento médio dos embrióides}

Para a variável comprimento do embrióides não houve interação significativa entre as concentrações de cinetina e $\mathrm{GA}_{3}$.

Maior comprimento do embrião $(3,6)$ foi observado quando se utilizou $8 \mathrm{mg} \mathrm{L}^{-1}$ de cinetina, 8,0 $\mathrm{mg} \mathrm{L}^{-1}$ de ANA e ausência de $\mathrm{GA}_{3}$ (Figura 4). Quando se utilizou $4 \mathrm{mg} \mathrm{L}^{-1}$ de cinetina obteve-se a formação de 3,2 embriões. Desta forma, como a diferença é mínima, justifica-se a adição de $4 \mathrm{mg} \mathrm{L}^{-1}$ de cinetina ao meio de cultura, com o objetivo de redução de custos. Na ausência de cinetina observou-se que o comprimento do embrião foi inferior a $2,8 \mathrm{~mm}$.

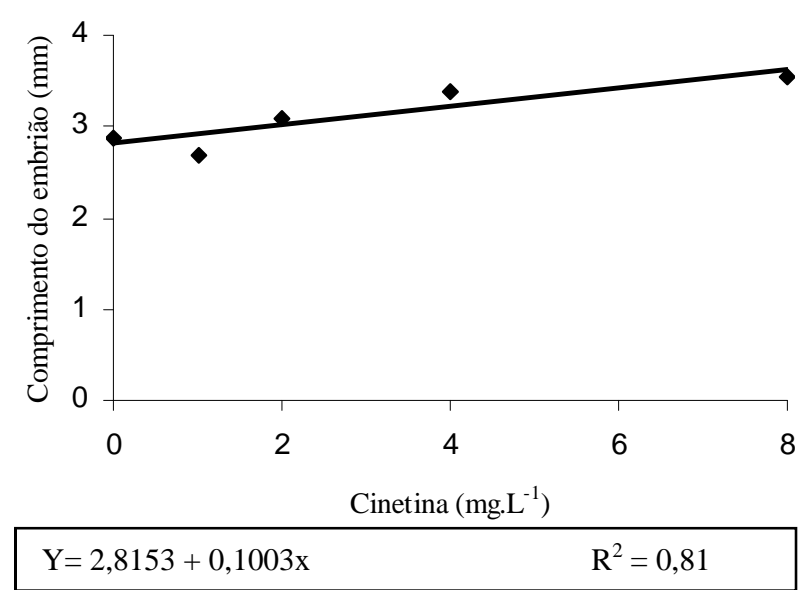

FIGURA 4 - Efeito de concentrações de cinetina, 8,0 $\mathrm{mg} \mathrm{L}^{-1}$ de ANA e ausência de $\mathrm{GA}_{3}$ no comprimento de embriões somáticos da Coffea arabica cv. Acaiá Cerrado. UFLA, Lavras-MG, 2004.

À medida que concentrações de $\mathrm{GA}_{3}$ foram aumentadas, observou-se aumento no comprimento do embrióide (Figura 5) até o valor de $4,47 \mathrm{~cm}$, quando se utilizou $17 \mathrm{mg} \mathrm{L}^{-1}$ de $\mathrm{GA}_{3}, 8,0 \mathrm{mg} \mathrm{L} \mathrm{m}^{-1}$ de ANA e ausência de cinetina. A partir desse ponto houve redução, provavelmente devido ao efeito fitotóxico do regulador de crescimento $\mathrm{GA}_{3}$. Quando o comprimento do embrióide formado é muito pequeno, é necessário maior tempo de permanência no meio de cultura, em torno de três meses, e quando esse é reduzido no laboratório há otimização da produção e redução de gastos. 


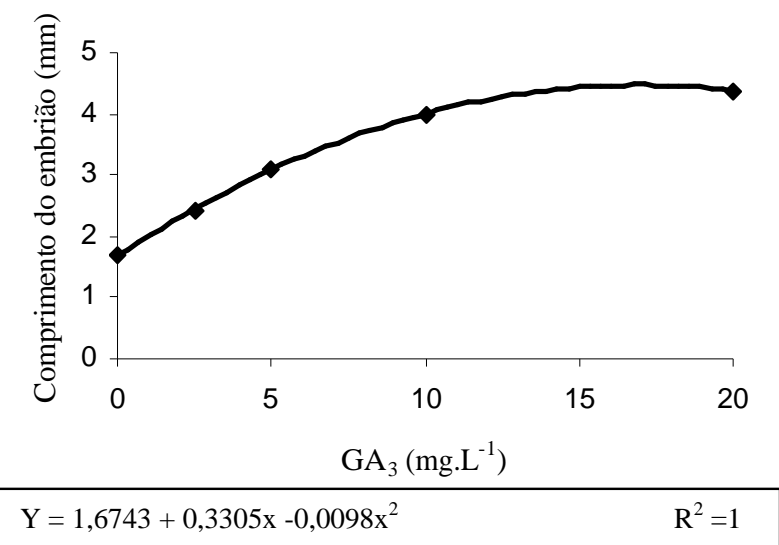

FIGURA 5 - Efeito de concentrações de $\mathrm{GA}_{3}, 8,0 \mathrm{mg} \mathrm{L}^{-1} \mathrm{de}$ ANA e ausência de cinetina no comprimento de embriões somáticos da Coffea arabica cv. Acaiá Cerrado. UFLA, Lavras-MG, 2004.

\section{CONCLUSÃO}

A ação combinada entre cinetina, $\mathrm{GA}_{3}$ e a auxina ANA estimula a indução de embriões somáticos pela via direta.

\section{REFERÊNCIAS BIBLIOGRÁFICAS}

ALMEIDA, J. A. J.; SIMIONI, K. C.; FAZUOLI, L. C.; RAMOS, L. C. S. Indução de calos de explantes foliares de genótipos de café. In: SIMPÓSIO DE PESQUISA DOS CAFÉS DO BRASIL, 1., 2000, Poços de Caldas. Resumos... Poços de Caldas: Embrapa-Café, 2000. v. 1, p. 145-147.

CARVALHO, G. R.; PASQUAL, M.; GUIMARÃES, R. J.; MENDES, A. N. G.; ANTUNES, L. E. C.; SILVA, A. T. da. Efeito do ácido giberélico e benzilaminopurina no crescimento in vitro de embriões do cafeeiro cv. Acaiá. Pesquisa Agropecuária Brasileira, Brasília, v. 33, n. 6, p. 847-851, 1998.

CORDEIRO, A. T. Embriogênese somática indireta e fusão interespecífica de protoplastos em Coffea. 1999. $111 \mathrm{f}$. Tese (Doutorado em Fisiologia Vegetal) - Universidade Federal de Viçosa, Viçosa, 1999.

DUBLIN, P. Tequiniques de reproduction vegétative "in vitro" et amelioration genétique chez les cafélers cultives. Café, Cacao, Thé, Paris, v. 28, n. 4, p. 231-244, 1984.
FUENTES, S. R. L.; CALHEIROS, M. B. P.; MANETTIFILHO, L.; VIEIRA, L. G. E. The effects of silver nitrate and different carbohydrate sources on somatic embryogenesis in C. canephora. Plant Cell, Tissue and Organ Culture, Dordrecht, n. 60, p. 5-13, 2000.

GUERRA, M. P.; TORRES, A. C.; TEIXEIRA, J. B. Embriogênese somática e sementes sintéticas. In: TORRES, A. C.; CALDAS, L. S.; BUSO, J. A. (Eds.). Cultura de tecidos e transformação genética de plantas. Brasília, DF: Embrapa, 1999. v. 2, p. 533-568.

HATANAKA, T.; ARAKAWA, O.; YASUDA, T.; UCHIDA, N.; YAMAGUCHI, T. Effect of plant growth regulators on somatic embryogenesis in leaf cultures of Coffea canephora. Plant Cell Reports, [S.1.], v. 10, p. 179-182, 1991.

MACIEL, A. L. de R.; PASQUAL, M.; PEREIRA, A. R.; REZENDE, J. C. de; SILVA, A. B.; DUTRA, L. F. Embriogênese somática indireta em explantes foliares de Coffea arábica L. Cv. Obatã. Ciência e Agrotecnologia, Lavras, v. 27, n. 1, p. 107-116, 2003.

MURASHIGE, T.; SKOOG, F. A. A revised medium for rapid growth and bioassays with

tabaco tissue cultures. Physiologia Plantarum, Copenhagen, v. 15, p. 473-497, 1962.

SHARP, W. R.; SONDAHL, M.; CALDAS, L. S.; MARAFFA, S. B. The physiology on in vitro assexual embryogenesis. Horticultural Review, New York, v. 2, p. 268-310, 1980.

SREENATH, H. L. Biotechnology for genetic improvement of Indian coffee. In: INTERNATIONAL SEMINAR ON BIOTECHNOLOGY IN THE COFFEE AGROINDUSTRY, 3 ., 1999, Londrina. Proceedings... Londrina: IAPAR/IRD, 2000. p. $247-250$.

STARISKY, G. Embryoid formation in callus culture tissue of coffea. Acta Botanica Neerlandica, Netherlands, v. 19, n. 4, p. 509-514, 1970.

VIEIRA, L. G. E.; KOBAYASHI, A. K. Micropropagação do cafeeiro. In: SIMPÓSIO DE PESQUISAS DOS CAFÉS DO BRASIL, 1., 2000, Poços de Caldas. Palestras... Poços de Caldas: [s.n.], 2000. p. 147-167. 